\title{
Why some faces will not be remembered: current ERP evidence on memory encoding for other-race and other-age faces
}

\author{
Stefan R. Schweinberger* and Holger Wiese \\ DFG Research Unit Person Perception, Friedrich Schiller University, Jena, Germany \\ *Correspondence: stefan.schweinberger@uni-jena.de
}

\section{A commentary on}

Why some faces won't be remembered: brain potentials illuminate successful versus unsuccessful encoding for same-race and other-race faces

by Lucas, H. D., Chiao, J. Y., and Paller K. A. (2011). Front. Hum. Neurosci. 5:20. doi: 10.3389/fnhum.2011.00020

The paper by Lucas et al. (2011) reports a very thorough assessment of the encoding of own- and other-race faces. This appears to be the first study assessing if and how the deficit in recognizing other-race faces is related to difficulties in facial encoding, as reflected in the Dm (Difference dependent on subsequent memory performance) ERP component. The study is in the tradition of Paller's seminal work on the Dm (Paller et al., 1987, 1988; Paller, 1990) as well as Sommer's early research on the Dm in face encoding (Sommer et al., 1991, 1995, 1997). The paper by Lucas et al. (2011) is broadly in line with a framework in which the degree of individuation at encoding is critical for successful subsequent recognition of a face. A distinctive feature of this paper is that, even though ERPs were collected and reported for Caucasian participants only, further behavioral work nicely demonstrates a fully crossed pattern of the own-race bias in memory for the stimuli used. Although it is not possible to directly correlate individual own-race bias to ERP parameters in the sample tested, this behavioral work demonstrates the validity of the general procedure.

Understanding the mechanisms mediating impaired memory for people from other groups is of significant importance, and such effects have been variously explained by either insufficient perceptual expertise of other-race faces, or by socio-cognitive factors by which social categorization into a group of people other than the observer's own leads to different processing and insufficient individual processing of the face in particular (Bernstein et al., 2007; Rhodes et al., 2010). In this commentary we would like to briefly discuss current ERP research on the other-race effect in face recognition, and to relate this to similar recent research on the potentially related phenomenon of the so-called other-age effect.

The other-age effect (or own-age bias) refers to the observation that participants are often better to recognize faces of their own-age group. In the first ERP study on this effect (Wiese et al., 2008), a strong other-age effect was observed for young participants, in that their memory performance for memorized young faces was substantially better compared to old faces. By contrast, elderly participants showed no significant other-age effect. Although the Dm was not studied in that paper, the authors noted that a number of ERP components appeared related to the own-age bias in young participants. First, young participants exhibited larger occipitotemporal P2 responses to young than old faces. Intriguingly, the P2 was also shown to be sensitive to a participant's expertise with race of a face, both in other studies from our lab (Stahl et al., 2008, 2010) and in Lucas et al. (2011)'s paper. In the study by Wiese et al. (2008), the right occipitotemporal N250 and a subsequent parietal old/ new effect recorded during the test phase also appeared to be sensitive to the ownage bias in face recognition. These two ERP components were thought to reflect facilitated access to perceptual representations and enhanced episodic retrieval, respectively, for faces from our young participants' own-age group.

We note that the similar patterns of earlier occipitotemporal (P2, N250) ERPs in particular could provide initial neurophysiological support for the idea that the own-race bias and the own-age bias in face recognition are mediated by the same, or at least very similar mechanisms. We believe that studies are needed that more directly compare the own-age and own-race bias in the same experiment, and that assess the Dm component in addition to the "standard" study and test phase ERPs. This should further elucidate the degree to which those powerful determinants of face memory are based on similar underlying mechanisms of perceptual encoding.

\section{REFERENCES}

Bernstein, M. J., Young, S. G., and Hugenberg, K. (2007). The cross-category effect - mere social categorization is sufficient to elicit an own-group bias in face recognition. Psychol. Sci. 18, 706-712.

Lucas, H. D., Chiao, J. Y., and Paller, K. A. (2011). Why some faces won't be remembered: brain potentials illuminate successful versus unsuccessful encoding for same-race and other-race faces. Front. Hum. Neurosci. 5:20. doi: 10.3389/ fnhum.2011.00020

Paller, K.A. (1990). Recall and stem-completion priming have different electrophysiological correlates and are modified by directed forgetting. J. Exp. Psychol. Learn. Mem. Cogn. 16, 1021-1032.

Paller, K. A., Kutas, M., and Mayes, A. R. (1987). Neural correlates of encoding in an incidental learning paradigm. Electroencephalogr. Clin. Neurophysiol. 67, 360-371.

Paller, K. A., McCarthy, G., and Wood, C. C. (1988). ERPs predictive of subsequent recall and recognition performance. Biol. Psychol. 26, 269-276.

Rhodes, G., Lie, H. C., Ewing, L., Evangelista, E., and Tanaka, J. W. (2010). Does perceived race affect discrimination and recognition of ambiguous-race faces? A test of the sociocognitive hypothesis. J. Exp. Psychol. Learn. Mem. Cogn. 36, 217-223.

Sommer, W., Heinz, A., Leuthold, H., Matt, J., and Schweinberger, S. R. (1995). Metamemory, distinctiveness, and event-related potentials in recognition memory for faces. Mem. Cognit. 23, 1-11.

Sommer, W., Komoss, E., and Schweinberger, S. R. (1997). Differential localization of brain systems subserving memory for names and faces with event-related potentials. Electroencephalogr. Clin. Neurophysiol. 102, 192-199.

Sommer, W., Schweinberger, S. R., and Matt, J. (1991). Human brain potential correlates of face encoding 
into memory. Electroencephalogr. Clin. Neurophysiol. $79,357-363$.

Stahl, J., Wiese, H., and Schweinberger, S. R. (2008). Expertise and own-race bias in face processing: an event-related potential study. Neuroreport 19, 583-587.

Stahl, J., Wiese, H., and Schweinberger, S. R. (2010). Learning task affects ERP-correlates of the own-race bias, but not recognition memory performance. Neuropsychologia 48, 2027-2040.
Wiese, H., Schweinberger, S. R., and Hansen, K. (2008). The age of the beholder: ERP evidence of an ownage bias in face memory. Neuropsychologia 46, 2973-2985.

Received: 11 May 2011; accepted: 19 August 2011;published online: 08 September 2011.

Citation: Schweinberger SR and Wiese H (2011) Why some faces will not be remembered: current ERP evidence on memory encoding for other-race and other-age faces. Front. Neurosci. 5:104. doi: 10.3389/ fnins.2011.00104

Copyright $\odot 2011$ Schweinberger and Wiese. This is an open-access article subject to a non-exclusive license between the authors and Frontiers Media SA, which permits use, distribution and reproduction in other forums, provided the original authors and source are credited and other Frontiers conditions are complied with. 